\title{
FEATURES OF THE TRANSFORMATION OF SMALL WATER DROPLETS AND LARGE WATER BOMBS IN FREE FALL
}

\author{
Roman S. Volkov ${ }^{\mathrm{a}}$, Pavel A. Strizhak \\ National Research Tomsk Polytechnic University, 634050 Tomsk, Russia
}

\begin{abstract}
This paper presents a series of experimental studies to determine the basic characteristics and features of the transformation of small water droplets $(3-6 \mathrm{~mm})$ and large water bombs $(50-100 \mathrm{~mm})$ in free fall. Investigations have been carried out using cameras "Phantom V411" and "Phantom Miro M310". Software "Tema Automotive" have been used for data processing from video recordings. The regulations of the surface transformations of small droplets and large water bombs have been established. The stages of transformation (disintegration) have been established for large water bombs. The mechanisms of deformation have been defined for small droplets. The characteristic times have been determined for the defined stages of transformation. The study demonstrates the influence of the initial size of droplets and water bombs on the times and velocities of considered processes.
\end{abstract}

\section{Introduction}

To date, the features of the transformation of large water bombs in free fall have not been fully investigated. However, this process is of interest to a number of technologies and industries. In particular, large water bombs released from aircraft into rapidly spreading fires are used in firefighting. At the same time, the mechanisms of large water mass moving and its further disintegration into small droplets have not been fully studied.

The investigation of motion and subsequent transformation of droplets, separated from the main shell after its breaking, also plays an important role in studying fire suppression. The motion of droplets under the influence of aerodynamic forces, acoustic emission and other "disturbing effects" is a specific sequence of "deformation cycles". The sequence is characterized by repeating the corresponding forms of droplets. This phenomenon has been demonstrated in works [1-6]. The term "deformation cycle" [3] means a time interval $t_{\mathrm{d}}$, when a droplet takes twice consecutively a shape similar to identical (in size, the axis of symmetry and other features) during its motion. However, it has not been fully studied to date, how fluid properties influence the characteristics of small (3-6 mm) droplets transformation. It is of interest to determine the effect of the sizes and velocities of a large water mass and droplets separated from it on the characteristics of their transformation in a gas medium. The effect may be observed in high slow motion from videos obtained by high-speed video recording. Thereby, it will be possible to choose the most common sizes and velocities of water bombs and droplets. The obtained data may be used to simulate appropriate processes in various

\section{${ }^{a}$ Corresponding author: romanvolkov@tpu.ru}


applications, as well as to establish the times of transitions from one form to another during water bombs or droplets motion.

The aim of this work is to investigate experimentally the features of the form transformation of small droplets and water bombs in free fall in the air. To obtain accurate results, it is appropriate to conduct experiments using high-speed video recording tools.

\section{Experimental setup and procedure}

Figure 1 shows the scheme of a setup used in our experiments. Registration tools were similar to facilities that we used in works [7-9]. There are two high-speed (up to $10^{5} \mathrm{fps}$ ) cameras in our setup: "Phantom V411" and "Phantom Miro M310". In contrast to our previous experiments [7-9], we used software "Tema Automotive" $[10,11]$ for data processing from video recordings. With the help of this software we could observe a continuously moving water bomb or individual droplets.

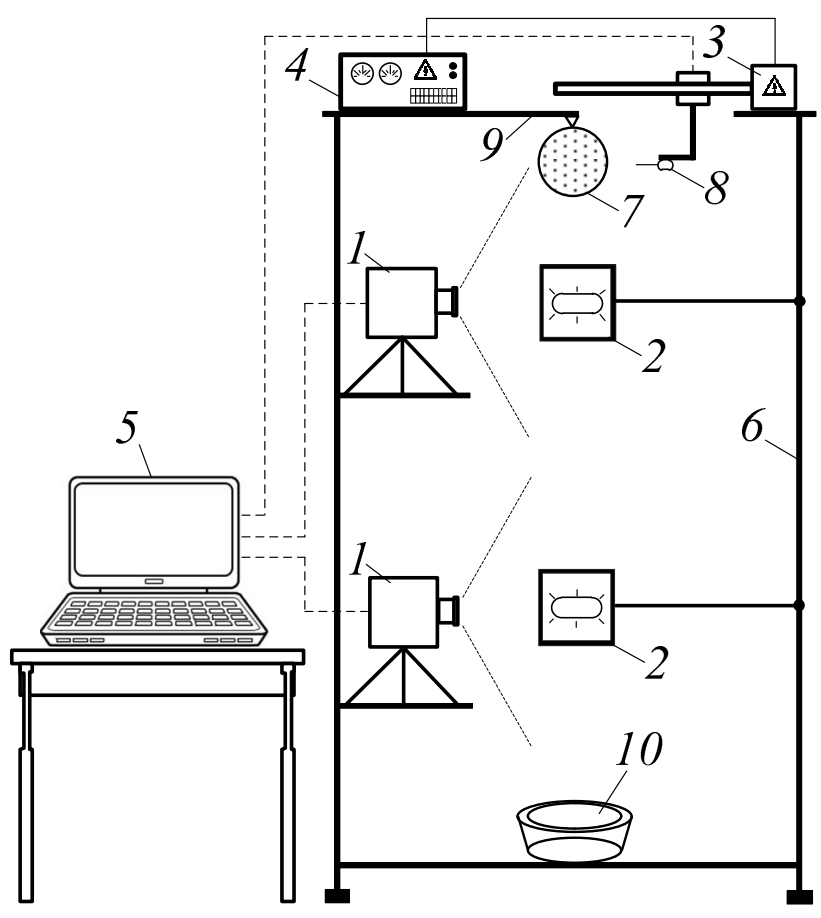

Figure 1. Scheme of an experimental setup: 1 - high-speed cameras; 2 - spotlights; 3 - motorized pointing device; 4 - power supply unit for a pointing device; 5 - personal computer; 6 - framework of an experimental setup; 7 - water bomb; 8 - holder with a fixed needle; 9 - metal rod for fastening a rubber shell; 10 - water catcher.

A spherical water bomb was made of a rubber shell (a finger cot) filled with water (the volume of water can be from 0.05 to $0.5 \mathrm{~L}$, depending on requirements). A single-channel dosing devise "Finnpipette Novus" was used to vary the volume of water. When the rubber shell was filled with water, it was fixed on a special rod 9. An automated sliding element 3 (a pointing mechanism "Polis") moved a holder with a fixed on it steel needle 8 in the direction of the water bomb. The needle pierced the rubber shell, thus, the breaking of the rubber shell was initiated (similar to experiments [12]). The parts of the rubber shell broke away from a water bomb surface within a few milliseconds after its breaking. The water bomb began to move under gravitational force (the height, where the water bomb was hung, was $3 \mathrm{~m}$ relative to the base of the setup). The motion of the water bomb, its deformation 
and disintegration were recorded by two cameras ("Phantom V411" and "Phantom Miro M310"). The cameras were set at different heights. Therefore, it was possible to observe the whole path of the falling water bomb (Fig. 1). Video cameras were placed at the same level to ensure 3D-registration in controlled experiments. The angle between the optical axes of cameras was $90^{\circ}[10,11]$.

The initial size of the water bomb varied from 50 to $100 \mathrm{~mm}$. It was carried out not less than 10 experiments for each characteristic volume of the water bomb. The shape of the water bomb was irregular in some experiments after the rubber shell broke. The shape was different from a spherical shape due to disturbances caused by the movement of shell parts. We used thin rubber shells. As a result, the number of experiments with irregular parameters did not exceed, as a rule, 3-4 out of 10 . We did not take into account the results of such experiments. We performed the analysis of video recordings when the water bomb had a spherical shape. We recorded the size of the water bomb and single droplets, their velocities, and the times of the defined stages of their surfaces transformation.

Systematic errors did not exceed $2 \cdot 10^{-4} \mathrm{~s}$ in time, $0.1 \mathrm{~mm}$ in size, when the size of the water bomb, separated droplets and their agglomerates were measured. The maximum error was $0.05 \mathrm{~m} / \mathrm{s}$, when the velocities of the water bomb and single droplets were determined.

\section{Results and discussion}

Figure 2 shows the typical states of the water bomb before and $20 \mathrm{~ms}$ after it has been released. It can be seen, that the water bomb is nearly spherical in shape at the initial stage. However, the water bomb becomes nearly flat after about $100-150 \mathrm{~ms}$ of its moving under gravity. It takes a shape similar to "a disk" or "a pancake". We analyzed the process of the gravitational precipitation of the water bomb in order to define the regularities of its transformation and disintegration.



(a)



(b)

Figure 2. Video frames of a water bomb $\left(d_{0}=70 \mathrm{~mm}\right)$ at the time when it is at rest in a rubber shell on a special $\operatorname{rod}(a)$ and $20 \mathrm{~ms}$ after it has been released $(b)$.

Our study have established the regularities of the surface deformation of a large water bomb $\left(d_{0}>50 \mathrm{~mm}\right.$ ) during its moving with moderate velocities (up to $8 \mathrm{~m} / \mathrm{s}$ ) in the air. The methods for analyzing the results of our experiments were similar to that we used to study the surface deformation of single droplets [13, 14]. Analyzing the video frames of our experiments, four characteristic stages may be identified. These stages describe the disintegration of the water bomb during its gravitational precipitation. Figure 3 shows the video frames of the deformation and disintegration of the water bomb for each defined stage (or phase).

There are four following processes associated with each defined stage (phase) of disintegration: 
1. The "flattening" of the water bomb (the phase of "quiet" motion): a gradual flattening of a water mass, until it takes a shape similar to "a disk" or "a pancake"; the formation of "necks" (narrow streams, which divide larger parts of the water bomb); the separation of small parts from the water mass.

2. The formation of bubbles (the phase of "moderate" disintegration): the beginning of bubbles formation and their subsequent increase, wherein the bulk of water is usually concentrated on the periphery of the water bomb (a liquid "torus").

3. The disintegration of bubbles and the formation of water "chains" (the phase of "intensive" disintegration): the rupture of bubbles (usually occurs from the central part of a bubble), and the formation of droplet sprays and water chains.

4. The formation of a cloud of small droplets (the phase of "complete" disintegration): splitting the water mass into many parts of small droplets fragments (as a result of the intensification of the processes in previous three phases).

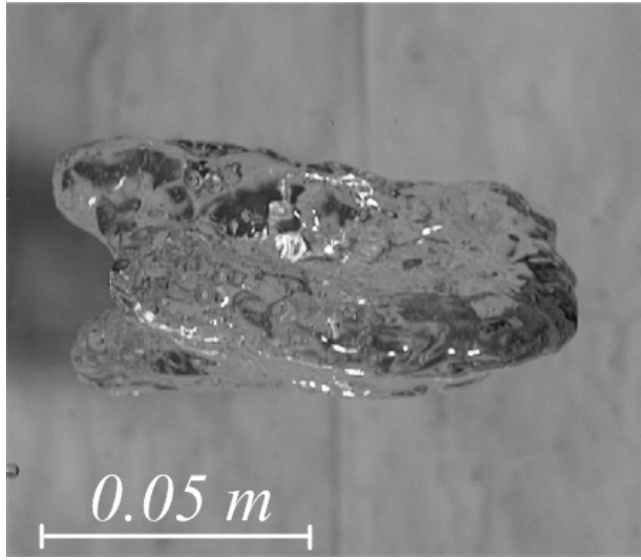

(a)



(c)

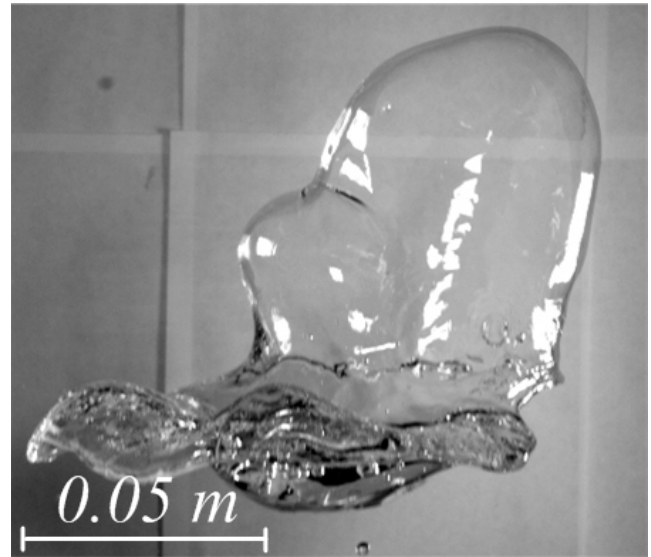

(b)

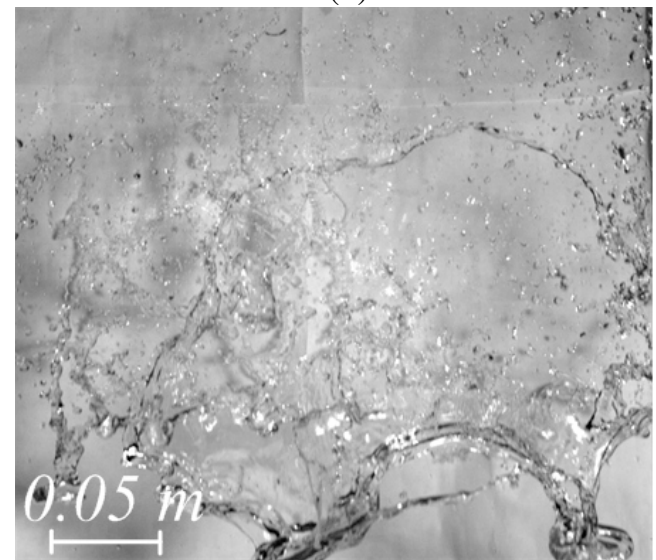

$(d)$

Figure 3. Video frames of a water bomb $\left(d_{0} \approx 70 \mathrm{~mm}\right)$ at different stages of its disintegration: $a$ - "flattening" of a water bomb, $b$ - formation of bubbles, $c$ - disintegration of bubbles and formation of water "chains", $d-$ formation of a cloud of small droplets.

Each subsequent phase of disintegration involves processes inherent to previous stages. For example, the "flattening" of the water mass, the formation of "necks" and the separation of small parts are observed throughout the motion of the water mass until its complete disintegration. The formation of "necks", as well as the separation of small parts, is intensified particularly with the growth and 
rupture of bubbles (the second and third phase). The formation and growth of bubbles is often observed simultaneously with their rupture. Therefore, phases 2 and 3 occur almost simultaneously. The fourth phase is observed at the intensification of bubbles explosion, when two or more bubbles explode at the same time. Thus, the water mass is divided into many small droplets $(1-8 \mathrm{~mm})$ and individual agglomerates with the size from 10 to $30 \mathrm{~mm}$.

Our previous experiments with single droplets $[13,14]$ demonstrated that the variety of individual (non-recurring geometry, position and size) droplets shapes (sphere, ellipsoid, or "a pancake") took place. In contrast to these experiments, only two typical shapes can be defined for large water bombs: a sphere (Fig. 2) and "a pancake" or oblate spheroid (Fig. 3a). As can be seen from our previous investigations [13, 14], the number of such shapes decreased with each subsequent cycle. For the first cycles we distinguished about ten individual forms, for the tenth and subsequent cycles - no more than five.

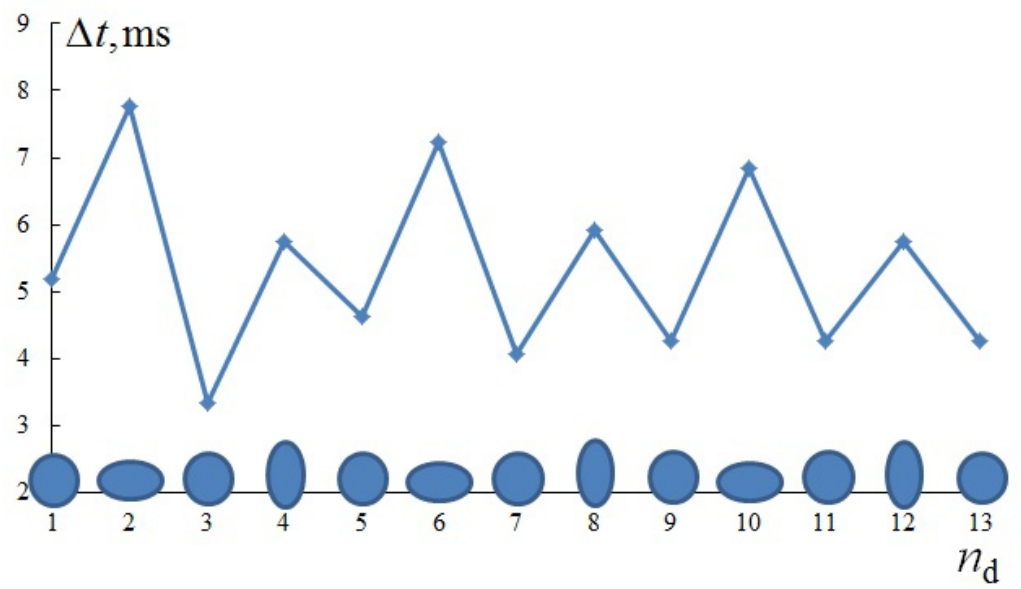

(a)

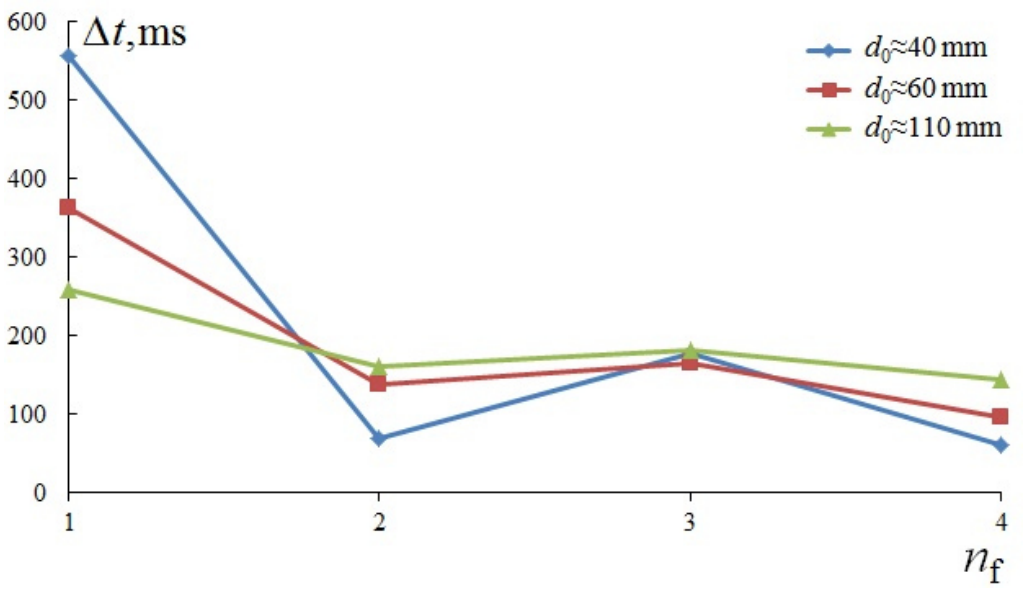

(b)

Figure 4. The characteristic times between the form transitions of individual small water droplets $(a)$ within 911 deformation cycles; the times between the stages of large water bomb disintegration; $(b): n_{\mathrm{d}}-$ serial number of a droplet shape; $n_{\mathrm{f}}-$ number of the phase of water bomb disintegration.

The experiments set the minimum and maximum amount of separated single droplets and agglomerates at each stage. In particular, the following sizes of agglomerates are typical for different stages: for the first stage 4-30.1 mm, for the second - from $3.6 \mathrm{~mm}$ to $32.3 \mathrm{~mm}$, for the third - from 
$3.2 \mathrm{~mm}$ to $28.1 \mathrm{~mm}$, for the fourth - a cloud of droplets with a size less than $6 \mathrm{~mm}$ (the nominal diameter of such clouds can reach 0.5 meters). As mentioned before, droplets take different shapes during the disintegration of a water bomb. It should be noted, that such shapes correspond to droplet shapes, illustrated in our previous works $[13,14]$. Separated droplets $\left(d_{0}<8 \mathrm{~mm}\right)$ are continuously deforming when moving. It can be associated with deformation modes [13, 14], especially with the second "rotational" mode (the rotation of an ellipsoidal droplet about its center of mass during motion).

Figure 4 shows the characteristic times between the form transitions of individual small water droplets $\left(d_{0} \approx 4 \mathrm{~mm}\right)$ and the times between the stages of large water bomb $\left(40<d_{0}<110 \mathrm{~mm}\right)$ disintegration.

As can be seen from Figure 4, the times of the deformation of small water droplets are much shorter (50-100 times) than the times between the phase transitions of the disintegration of a large water bomb. This difference in times is primarily due to the fact, that there is a big difference in sizes of the compared volumes of water (the difference is not less than 10 times). Therefore, the maximum Weber number for single droplets in the considered segment of their motion is $\mathrm{We}_{\mathrm{mw}}=u_{\mathrm{m}}{ }^{2} d_{\mathrm{m}} \rho_{\mathrm{a}} / \sigma_{\mathrm{lw}}==5^{2} \cdot 6 \cdot 10^{-3} \cdot 1,5 / 0,0618 \approx 3,64$. We carried out experiments under the following conditions: the maximum air density was $\rho_{\mathrm{a}} \approx 1,5 \mathrm{~kg} / \mathrm{m}^{3}$, the coefficient of water surface tension was $\sigma_{\mathrm{lw}}=0,0618 \mathrm{~kg} / \mathrm{s}^{2}$.

Our research suggests that the continuous motion of a water mass (from 50 to $300 \mathrm{~mL}$ ) during at least 4-5 min can lead to their complete disintegration into droplets $(1-8 \mathrm{~mm})$. Small water volumes separate from a relatively large water mass. This leads to the disintegration of water agglomerates. When agglomerates disintegrate into smaller parts, the process is repeated, until the entire volume of water fully disintegrates into small droplets.

\section{Conclusion}

This paper describes the macroscopic regularities of the desintegration of water bombs and small water droplets, and the features of their transformations. Investigations have been carried out using high-speed cameras "Phantom V411", "Phantom Miro M310" and software "Tema Automotive". With the help of this software it was possible to carry out continuous monitoring. The basic characteristics have been found (the shape, size and speed of a water bomb, the sizes of droplets and their agglomerates) for four defined stages. The study demonstrates that the features of the transformation of small water droplets in free fall correspond to previously defined cycles. The obtained results can be used to develop the technologies of fire extinguishing. Thus, it is possible to extinguish fire not only by pulsed sprayed liquid, but, for example, using jets, blurred water, water curtains or other configurations of water mass, which are traditionally used.

The investigation of the surface transformations of droplets and large water bombs was financially supported by the Russian Foundation for Basic Research (project 14-39-00003). The analysis of spraying and releasing droplets and water bombs was financially supported by the scholarship of the President of the Russian Federation for young scientists and graduate students (SP-2290.2015.1).

\section{References}

1. A.L. Gonor, V.Ya. Rivkind, Dinamika kapli (Results of Science and Technology, Fluid Mechanics) 17 (1982) [in Russian].

2. A. Wierzba, Exp. in Fluids 9, 1 (1990).

3. V.V. Dubrovskii, A.M. Podvysotskii, A.A. Shraiber, J. Eng. Phys. and Thermophys. 5, 58 (1990).

4. L.P. Hsiang, G.M. Faeth, Int. J. Multiph. Flow 5, 19 (1993).

5. A.A. Shreiber, A.M. Podvisotski, V.V. Dubrovski, Atomization and Sprays 6, 6 (1996).

6. S.S. Hwang, Z. Liu, R.D. Reitz, Atomization Sprays 6 (1996). 
7. R.S. Volkov, G.V. Kuznetsov, P.A. Strizhak, Thermophys. and Aeromech. 2, 21 (2014).

8. R.S. Volkov, G.V. Kuznetsov, P.A. Strizhak, Int. J. Heat Mass Transfer 79 (2014).

9. O.V. Vysokomornaya, G.V. Kuznetsov, P.A. Strizhak, Fire Saf. J. 70 (2014).

10. J. Janiszewski, Metrol. and Measur. Sys. 4, 19 (2012).

11. J. Janiszewski, Int. J. Solids and Struct. 7-8, 49 (2012).

12. E.E. Meshkov, V.O. Oreshkov, G.M. Yanbayev, Techn. Phys. Lett. 8, 37 (2011).

13. R.S. Volkov, A.O. Zhdanova, P.A. Strizhak, EPJ Web of Conferences. Conference on ThermoPhys. Basis of Energy Technologies 76, 01038 (2014).

14. R.S. Volkov, G.V. Kuznetsov, P.A. Strizhak, Int. J. Heat Mass Transfer 85 (2015). 